\title{
Influence of operational conditions of scalding in the quality of broiler carcasses in industrial scale
}

\author{
Edson Anghinoni, Daniele Hamann, Rogério Luis Cansian, Alexander Junges, Eunice Valduga, \\ Clarice Steffens*
}

Department of Food Engineering, URI Erechim, Av. Sete de Setembro 1621, Erechim-RS 99700000, Brazil

\section{A B S T R A C T}

\begin{abstract}
The processing steps as scalding and de-feathering in the poultry industry have a great impact in meat quality. In this sense, the aim of this work is to evaluate the temperature effect $\left(52,57\right.$ and $\left.62^{\circ} \mathrm{C}\right)$, broiler weight $(2.4-2.6,2.8-3.0$ and $3.2-3.4 \mathrm{~kg})$ and broiler processing line speed $\left(4.000,6.500\right.$ and 9000 broilers/h) of the scalding and de-feathering in the meat quality. An experimental design $2^{3}$ was employed to evaluate the physical characteristics (absence of torn breast skin, epidermis, feather on wing and uropygium), color ( $\left.L^{*}, a^{*}, b^{*}\right)$, texture profile (hardness, adhesiveness, elasticity, cohesiveness, gumminess, chewiness, and resilience), and $\mathrm{pH}$ of broiler breast fillets. The $\mathrm{pH}$ did not suffer significant effect $(p>0.05)$ of the variables between the ranges studied. In general, the better meat quality was obtained at $57^{\circ} \mathrm{C}$ scalding temperature, $3.0-3.2 \mathrm{~kg}$ weight and 6500 broilers $/ \mathrm{h}$ processing line speed. In addition, these conditions are applicable to removal the epidermis, feather on wing and uropygium.
\end{abstract}

Keywords: Scalding; Temperature; Meat quality; Epidermis removal; Absence of feathers; Broiler

\section{INTRODUCTION}

The global food industry works in an environment with policies, standards, regulations, guidelines, education and advisory services, including food safety, which is continually being developed, and updated (King et al., 2017). In order to meet the nutritional and preferences of consumers, the agrifood sector is constantly restructured. The main challenges of the food industry are obtaining a trade-off between product price versus safety, quality, variety, and demand. To address these challenges, industry professionals are required to focus on each major area where a product is processed, stored and distributed (Lorenzetti et al., 2015, 2018; Carthy et al., 2018).

In the year of 2018 the food sector has stood out in the meats global production, commercializing around 335 million tons, of these, about 121.6 million were poultry, and $88 \%$ corresponds to the chicken market (FAO, 2018). In view of the high volume of meat processing in a poultry slaughterhouse, industrial designs and the automation of equipment can reduce labor costs and increase the efficiency of the production line.
One of the variables that influence the broiler processing and meat quality is the scald. The process is performed by immersing the broiler in warm water or steam exposure to loose the feathers. The temperature and time of scalding should be adjusted according to the broiler characteristics. The use of high temperature $\left(61-63^{\circ} \mathrm{C}\right)$ in the scalding can remove the outer epidermal layer of the skin and are more susceptible to the discoloration, while soft temperature $\left(50-54^{\circ} \mathrm{C}\right)$ does not remove the cuticle and the skin color are more yellow (Bowker, Zhuang and Buhr, 2014; Lorenzetti et al., 2018). In addition, for an effective scalding and product quality the broiler weight and processing line speed are important factors to be evaluated and adjusted for feathers removal by plucking equipment (Bowker and Zhuang, 2013; Barbut 2015). Zuang et al. (2013) evaluated the effects of broiler carcass in the scalding $\left(60^{\circ} \mathrm{C}\right.$ for $1.5 \mathrm{~min}$, and $52.8^{\circ} \mathrm{C}$ for $3 \mathrm{~min}$ ) and chilling methods $\left(0.5^{\circ} \mathrm{C}, 120 \mathrm{~min}\right.$ - air-chilled, and $0.5^{\circ} \mathrm{C}, 40 \mathrm{~min}$ immersionchilled in water and ice) on quality of broiler breast fillets and observed that these parameters influence the quality attributes (color, pH, drip loss, cook loss, and shear force). Buhr et al. (2014) did not observe significant difference in weight and yield of broiler carcasses using hard scalding

\footnotetext{
*Corresponding author:

Dr. Clarice Steffens, Department of Food Engineering, URI Erechim, Av. Sete de Setembro 1621, Erechim-RS 99700000, Brazil.

Tel.: 0555435209000. E-mail: clarices@uricer.edu.br
}

Received: 22 May 2019; $\quad$ Accepted: 29 October 2019 
$\left(60.0^{\circ} \mathrm{C}\right.$ for $\left.1.5 \mathrm{~min}\right)$ and soft scalding $\left(52.8^{\circ} \mathrm{C}\right.$ for $\left.3 \mathrm{~min}\right)$. Jeong et al. (2011) evaluated hard scalding $\left(56.7^{\circ} \mathrm{C}\right.$ for $\left.120 \mathrm{~s}\right)$ using water and soft scalding $\left(50^{\circ} \mathrm{C}\right.$ for $\left.220 \mathrm{~s}\right)$ using air and evaporative air chilling in the broiler carcass and verified that air chilling carcass showed a darker appearance, more yellow-skinned and a surface discolored in relation to the others treatments.

Even though scalding effects on broiler skin are known. So more studies are necessary to investigate the effects as temperature $\left(52,57\right.$ and $\left.62^{\circ} \mathrm{C}\right)$, weight $(2.4-2.6,2.8-3.0$ and $3.2-3.4 \mathrm{~kg})$ and processing line speed $(4.000,6.500$, and 9000 broilers/h) of the scalding and de-feathering in the meat product quality. The physical characteristics of broiler carcasses evaluated were the absence of torn breast skin, epidermis, feather on wing and uropygium), color $\left(L^{*}, a^{*}, b^{*}\right)$, texture profile (hardness, adhesiveness, elasticity, cohesiveness, gumminess, chewiness, and resilience), and $\mathrm{pH}$.

\section{MATERIAL AND METHODS}

\section{Selection and processing of broiler}

The male broilers of COBB line were selected on three tracks with weighing between 2.6 to 2.8 ; 3.0 to 3.2 ; and 3.4 to $3.6 \mathrm{~kg}$. Before slaughter, they were submitted to $8 \mathrm{~h}$ of food restriction, with access to water between 3 and $4 \mathrm{~h}$ after food withdrawal. The broilers were slaughtered in a poultry slaughterhouse, situated in the West of Santa Catarina (Brazil).

The broilers were individually weighed on a static balance (Libratec WT 3000 I) and inserted in the cut line, in batches of 31 broilers, and hung by their feet on the shackles of a conveyor with $15.2 \mathrm{~cm}$ of space. Next, stunned by an electric shock at $60 \mathrm{~V}$ and $850 \mathrm{~Hz}$ (Insensibilizador Fx. 3.0 CA - Industrial Electronic) under immersion in liquid, killed by cutting the carotid arteries (Meyn automatic knife), and allowed to bleed for 3 min. Next, they were scalded in five sequential tanks (capacity of $9.000 \mathrm{~L}$ ) in continuous regime (broiler scaling tanks, model 1.127.007.00328 - Semil Industrial Equipment), and de-feathered in an automated plucking equipment (Semil Equipamentos Industriais - 1,127,011.00008) equipped with rubber fingers (rub the feathers of the carcass) at $50 \pm 5^{\circ} \mathrm{C}$ (Barbut 2015). In the scalding tank, the immersion time was varied according to the broiler amount as follow: $72 \mathrm{~min}$ for 9000 broilers/h, $104 \mathrm{~min}$ for 6500 broilers/h, and $159 \mathrm{~min}$ for 4000 broilers/h. In the de-feathered stage, the residence time was $38 \mathrm{~s}$ for $9000 \mathrm{~s} / \mathrm{h}, 52 \mathrm{~s}$ for $6.500 / \mathrm{h}$, and $78 \mathrm{~min}$ for $4000 / \mathrm{h}$. The head was removed from the carcass and the feet were separated in the cut legs section (Meyn 0156-1). The carcasses followed to a cloaca extractor
(Meyn, 0101-2), abdomen opener (Scissor ECP - Meyn), eviscerator (Meyn, Meyn Maestro), being inspected and directed to the conveyor line, where the chest was separated.

The effects of the operational conditions of the scalding stage in the quality of broiler carcasses were evaluated. A factorial design $2^{3}$ was applied to evaluate the independent variables as temperature $\left(52,57\right.$, and $\left.62^{\circ} \mathrm{C}\right)$, weights $(2.6-2.8,3.0-3.2$, and 3.4-3.6 kg), and processing line speed (4000, 6500, and 9000 broilers/h). These conditions were chosen based on preliminary tests carried out in the poultry slaughterhouse. The fixed variables were an electric shock $(60 \mathrm{~V}$ and $850 \mathrm{~Hz})$, bleeding time ( $3 \mathrm{~min}$ ), volume of the scalding tank $(9000 \mathrm{~L})$, water temperature in the de-feathering $\left(50 \pm 5^{\circ} \mathrm{C}\right)$, and bubbling in the scalding tank $(11.7 \mathrm{kPa})$. In the experimental design, 31 broilers (samples) were used in each run. The dependent variables (responses) were the physical-chemical characteristics $\left(\mathrm{pH}\right.$, and color $\left.\mathrm{L}^{*}, \mathrm{a}^{*}, \mathrm{~b}^{*}\right)$, texture profile (hardness, adhesiveness, elasticity, cohesiveness, gumminess, chewiness, and resilience) visual aspects (integrity of the breast skin, presence of epidermis and absence of feather on wing and uropygium) of the raw samples.

\section{Analysis in the carcasses}

After de-feathering, the carcasses were classified with notes from 0 to 5 in relation to the remaining feathers on the wing and uropygium. Note 0 was given for a large number of feathers on the wing and uropygium (more than 4 follicles); 1 for a reasonable amount (2 or 3 follicles), 2 for few feathers ( 1 follicle), and 5 for no feathers. For the presence or absence of epidermis was adopted a pattern of notes from 0 to 5 ( 0 - Presence of epidermis and 5 - absence of epidermis). In the torn breast skin, a score of 0 was recorded when the presence of torn breast skin was noted and 5 when no torn was observed. The notes were converted into a percentage for subsequent data processing.

Analyzes of $\mathrm{pH}$, color $\left(\mathrm{L}^{*}, \mathrm{a}^{*}, \mathrm{~b}^{*}\right)$, and texture profile were performed in the middle of the broiler breast, in specific regions, as demonstrated in Fig. 1. The geometric shape was $4.0 \times 2.0 \times 2.0 \mathrm{~cm}$, always drawn from the same region of the middle of the breast (raw samples).

\section{Analytical determinations}

$\mathrm{pH}$ was analyzed by potentiometric according to the 981.12 method (AOAC, 2005). Instrumental color was determined using a colorimeter (Minolta CR400) with a D65 light source, expressing the results in CIELAB color space $\left(\mathrm{L}^{*}, \mathrm{a}^{*}, \mathrm{~b}^{*}\right)$, where $\mathrm{L}^{*}$ is the lightness or brightness (ranging from black-0 to white-100), $\mathrm{a}^{*}$ is the chromaticity coordinate (ranging from green $(-)$ to red $(+)$ ), and $\mathrm{b}^{*}$ is coordinated chromaticity (ranging from blue $(-)$ to yellow $(+)$ ). Instrumental analysis of texture (hardness, adhesiveness, elasticity, cohesiveness, gumminess, chewiness, and resilience) was determined by 
Texture machine (Stable Micro Systems model TA. XT), using a load cell with $10 \mathrm{~kg}$, a cylindrical stainless steel probe of $31.8 \mathrm{~mm}$ diameter (POR/6), $55 \mathrm{~mm}$ distance height of the probe, pretest speed $3.0 \mathrm{~mm} / \mathrm{s}$, test speed of $1.0 \mathrm{~mm} / \mathrm{s}$, post-test speed of $3.0 \mathrm{~mm} / \mathrm{s}$. Maximum force to compress $20 \%$ of the initial weight (maximum force required to compress initial weight was determined after preliminary testing) in $5 \mathrm{~s}$. The geometric shape of the middle chest (Fig. 1) evaluated was $4.0 \times 2.0 \times 2.0 \mathrm{~cm}$, always drawn from the same region of the middle of the breast (raw samples), whereas the compression was toward the top of the sample to the bottom.

\section{Statistical analysis}

The variance analysis followed by Tukey's post-hoc test were performed using the software Statistic 5.0 (Statsoft, USA) considering $95 \%$ confidence level $(p<0.05)$ and $90 \%$ $(p<0.1)$. Correlations between variables were established by correlation analyses using Pearson's coefficient and the same means were subjected to Principal Component Analysis (PCA) using Statistic 5.0 (Statsoft, USA).

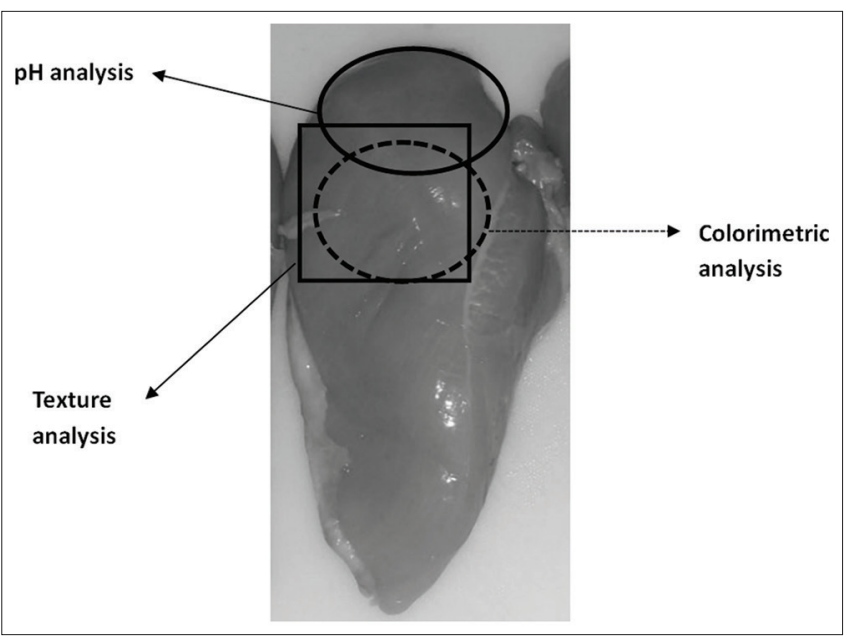

Fig 1. Sampling regions in the middle of broiler breast.

\section{RESULTS AND DISCUSSION}

Table 1 shows the experimental design of the $2^{3}$ matrix and the responses of $\mathrm{pH}$ and color $\left(\mathrm{L}^{*}, \mathrm{a}^{*}, \mathrm{~b}^{*}\right)$ of the broiler breast. The $\mathrm{pH}$ presented values between 5.83 and 6.31. Not was observed significant effect $(p>0.05)$ of the independent variables studied. The $\mathrm{pH}$ values found corroborate with a study performed by Santos, Brandelli and Ayub (2004), which found a variation from 5.5 to 6.3 in broiler fillets post-mortem depending on pre-slaughter conditions, meat physiology and biochemical.

Equation 1 shows the first order coded model for color $\mathrm{L}^{*}$ validated by variance analysis, and the non-significant parameters were added to the lack of fit in the ANOVA test. The correlation coefficient was 0.92 , and the F calculated value was 3.57 times higher than the $\mathrm{F}$ tabulated value. A contour curve was obtained (Fig. 2), that can be observed an increasing in the temperature and decreasing the broiler processing line speed resulted in an increase color $\mathrm{L}^{*}$.

$$
L^{*}=62.65+2.035 \mathrm{X}_{1}-2.24 \cdot \mathrm{X}_{3}-1.92 \cdot \mathrm{X}_{1} \cdot \mathrm{X}_{3}(1)
$$

where $\mathrm{X}_{1}=$ Temperature $\left({ }^{\circ} \mathrm{C}\right) ; \mathrm{X}_{3}=$ Processing line speed (broiler/h).

Chatterjee et al. (2016) classified the broiler breast fillets as white striping with color L* from 57.4 to 65.2 , normal between 49.1 to 56.1 , and dark from 40.7 to 51.4. In this way, the color $\mathrm{L}^{*}$ in present study can be considered high lightness (white). In the literature, some works related that the genotype of high-yield broiler presents high lightness, possibly due the changes in the integrity of the fibrous membrane, which contribute to the fluid loss (Soglia et al. 2016). Thus, explain the high reflectance, (high brightness values from 60.12 to 70.98 ) for the results found in the present study (Table 1). Color is an important attribute

Table 1: Matrix of the experimental design $2^{3}$ (real and coded values) and values of $\mathrm{pH}$, color $\left(\mathrm{L}^{*}, \mathrm{a}^{*}, \mathrm{~b}^{*}\right)$ of broiler breast

\begin{tabular}{|c|c|c|c|c|c|c|c|}
\hline \multirow[t]{2}{*}{ Runs } & \multicolumn{3}{|c|}{ Independents variables } & \multicolumn{4}{|c|}{ Response } \\
\hline & $X_{1}$ & $X_{2}$ & $X_{3}$ & $\mathrm{pH}$ & Color L* & Color $\mathrm{a}^{*}$ & Color b* \\
\hline 1 & $-1(52)$ & $-1(2.6-2.8)$ & $-1(4000)$ & 6.23 & 60.81 & 7.22 & 17.26 \\
\hline 2 & $-1(52)$ & $+1(3.4-3.6)$ & $-1(4000)$ & 6.10 & 61.59 & 6.36 & 15.88 \\
\hline 3 & $-1(52)$ & $-1(2.6-2.8)$ & $+1(9000)$ & 5.93 & 62.26 & 6.62 & 17.02 \\
\hline 4 & $-1(52)$ & $+1(3.4-3.6)$ & $+1(9000)$ & 5.87 & 60.22 & 6.55 & 16.29 \\
\hline 5 & $+1(62)$ & $+1(3.4-3.6)$ & $+1(9000)$ & 5.92 & 61.74 & 6.53 & 16.03 \\
\hline 6 & $+1(62)$ & $-1(2.6-2.8)$ & $+1(9000)$ & 5.97 & 67.91 & 3.27 & 13.98 \\
\hline 7 & $+1(62)$ & $-1(2.6-2.8)$ & $-1(4000)$ & 5.99 & 70.98 & 3.17 & 14.25 \\
\hline 8 & $+1(62)$ & $+1(3.4-3.6)$ & $-1(4000)$ & 6.12 & 60.51 & 5.84 & 13.79 \\
\hline 9 & $0(57)$ & $0(3.0-3.2)$ & $0(6500)$ & 5.83 & 62.11 & 7.20 & 15.06 \\
\hline 10 & $0(57)$ & $0(3.0-3.2)$ & $0(6500)$ & 6.10 & 60.12 & 7.25 & 16.18 \\
\hline 11 & $0(57)$ & $0(3.0-3.2)$ & $0(6500)$ & 6.31 & 61.44 & 7.27 & 15.70 \\
\hline 12 & $0(57)$ & $0(3.0-3.2)$ & $0(6500)$ & 6.16 & 62.07 & 7.09 & 17.35 \\
\hline
\end{tabular}

$\mathrm{X}_{1}=$ Temperature ${ }^{\circ} \mathrm{C}, \mathrm{X}_{2}=$ Broiler weight $(\mathrm{kg}), \mathrm{X}_{3}=$ processing line speed (broiler/h), Independent variables electric shock (60 $\mathrm{V}$ and $850 \mathrm{~Hz}$ ), bleed time ( $3 \mathrm{~min}$ ), volume in the scalding tank $(9000 \mathrm{~L})$, water temperature in the de-feather $\left(50 \pm 5^{\circ} \mathrm{C}\right)$ and bubbling in the scalding tanks $(11.7 \mathrm{kPa})$ and 31 broilers by run 
in breast fillets for customer satisfaction in the purchase (Droval et al. 2012), once depends on the amount of light scattered.

Qiao et al. (2001) also report a relation between $\mathrm{pH}$ and color, describing that the pallor meat may be linked to several factors, one of them is the protein denaturation caused by the low $\mathrm{pH}$ and the high temperature of the carcass. The color observed on the meat surface resulted from the absorption of myoglobin, caused by the distribution of the light, which comes out of the meat. Reduced $\mathrm{pH}$, protein denaturation and water expulsion increase the interaction between proteins, thus increasing birefringence, with less light being transmitted through the fibers and more light scattered.

The high lightness $\left(\mathrm{L}^{*}\right)$ in the sample was observed in high temperature and low broiler processing line speed in the scalding (Fig. 2). This fact can be associated with the protein denaturation (Ali et al., 2015), where the meat pigments are heated and denatured myoglobin. This denaturation results in meat with a structure more opaque, translucent in the raw state, and reflecting more light,

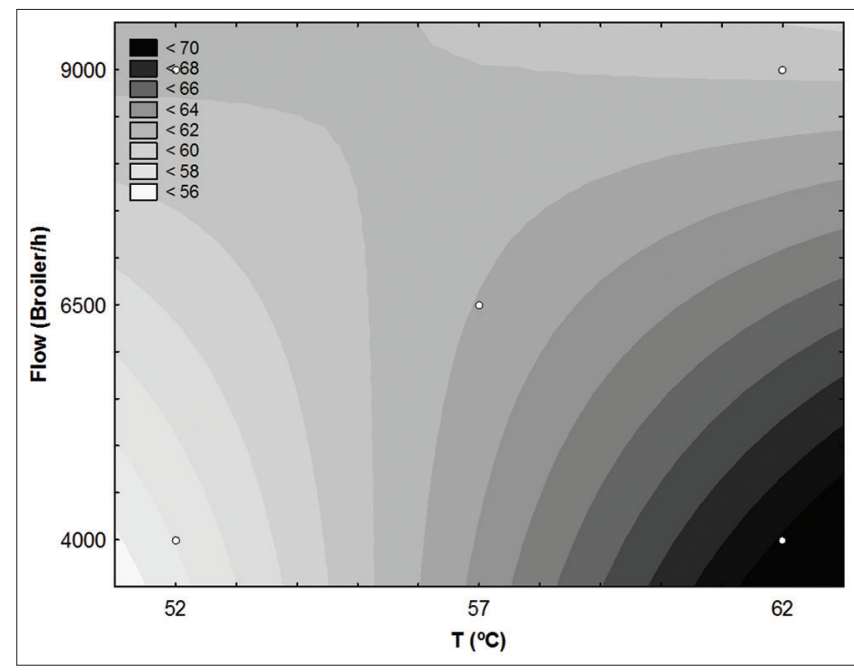

Fig 2. Contour curves of factorial design $2^{3}$, as a function of temperature and broiler processing line speed for the color $L^{*}$ in the broiler breast with L* value above 65 (Barbut 2015). In addition, the myoglobin denaturation can be correlated with the color a* (Table 1), where high temperature and low weight of broiler was employed in the scalding resulted in a breast with low values of color a* (Runs 6 and 7). According to King and Whyte (2006) the heat causes a change in the color, making them less red.

Fig. 3a shows a Pareto chart with the estimated effects (absolute value) in the factorial design $2^{3}$ for color $a^{*}$. It's possible to observe that the temperature, and the interaction between weight and processing line speed presented a significant negative effect $(p<0.05)$, while the processing line speed (flow), weight and the interaction effect between temperature and weight have a significant positive effect $(p<0.05)$, in color $a^{*}$ on the broiler breast. In this way the increase in the temperature change the red color. Also, the red color in the meat can be associated with age and physiological factors (Bowker and Zhuang, 2013). Breasts of raw broiler obtained commercially of different suppliers in relation to color showed values of $70.98 \mathrm{~L}^{*}$, $4.87 \mathrm{a}^{*}$, and $17.59 \mathrm{b*}$. The value of color $\mathrm{a}^{*}$ was similar to the present study (3.17 to 7.27) (Husak, Sebranek and Bregendahl, 2008).

The color $\mathrm{b}^{*}$ presented values between 13.79 to 17.35 (Table 1). The Pareto chart for color $b^{*}$ shows a negative effect $(p<0.1)$ only for the temperature (Fig. 3b). The other parameters did not show significant effect $(\mathrm{p}>0.1)$. Bowker, Zhuang and Buhr (2014) studied the effect of hard $\left(60^{\circ} \mathrm{C}, 1.5 \mathrm{~min}\right)$ or soft $\left(52.8^{\circ} \mathrm{C}, 3 \mathrm{~min}\right)$ scalded, and either immersion chilled $\left(0.5^{\circ} \mathrm{C}, 40 \mathrm{~min}\right)$ or air chilled $\left(0.5^{\circ} \mathrm{C}, 120 \mathrm{~min}\right)$ in breast fillets. The authors did not find a significant difference in the scalding and cooling variables on the color parameters $\left(\mathrm{L}^{*}, \mathrm{a}^{*}, \mathrm{~b}^{*}\right)$.

Thus, in all the experiments were observed an increase in the luminosity values and reduction of the red and yellow intensity with high temperature, and a reduction in the luminosity when the broiler processing line speed was increased. This can be evidenced in Fig. 4, where it is
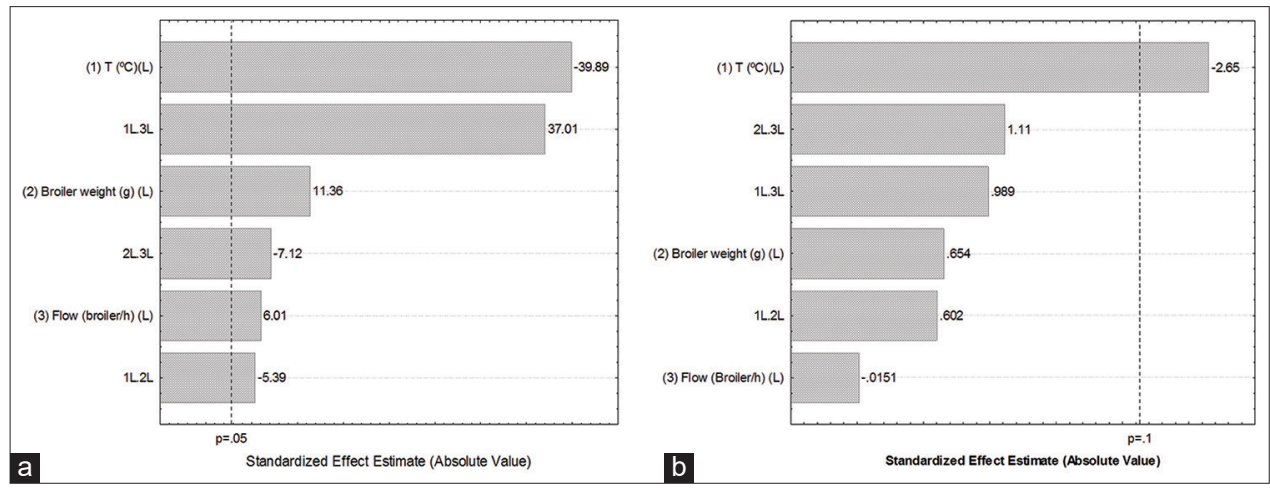

Fig 3. Pareto chart with the estimated effect (absolute value) for color $a^{*}(a)$ and color $b^{*}(b)$ in the broiler breast 
possible to visualize the differentiation on pigmentation intensity and brightness on the breast fillets without skin and bone obtained in the Runs 1, 9 and 7.

Table 1 shown the matrix of the experimental design $2^{3}$ (real and coded values) and the effects of scalding, broiler weight and broiler processing line speed in the breast fillet texture. The texture profile investigate are hardness, adhesiveness, elasticity, cohesiveness, gumminess, chewiness and resilience. For hardness, adhesiveness, elasticity and cohesiveness not were
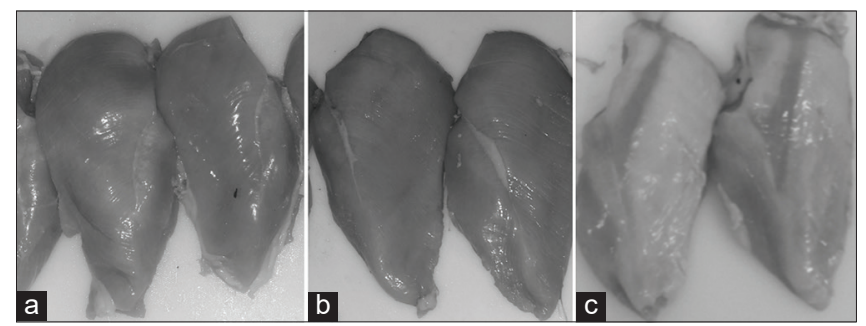

Fig 4. Visual aspect of the broiler breast without bone and skin. (a) Run 1; (b) Run 9, and (c) Run 7 observed significant effect $(\mathrm{p}>0.1)$ of studied variables (results not demonstrated).

For the gumminess (energy required to chew a semi-solid product) the broiler weight and the interactions between temperature and weight affected positively $(\mathrm{p}<0.10)$, and the interaction between temperature and flow affected negatively $(p<0.10)$ this parameter (Fig. 5a). Since modifications that leave the product pastier may result in low values of gumminess, that is, the variables can affect the sensory perception when swallowing the product, when they will be processed. Chatterjee et al. (2016) evaluated the texture properties (hardness, chewiness, adhesiveness, and springiness) of raw and cooked broiler fillets and showed significant difference between the samples. They related that cooked fillets were harder, more adhesive and chewy, and less springy than raw broiler fillets.

The chewiness (Fig. 5b), energy needed to chew a solid food in a ready-to-swallow state) was affected by the broiler weight and the interactions between the temperature and

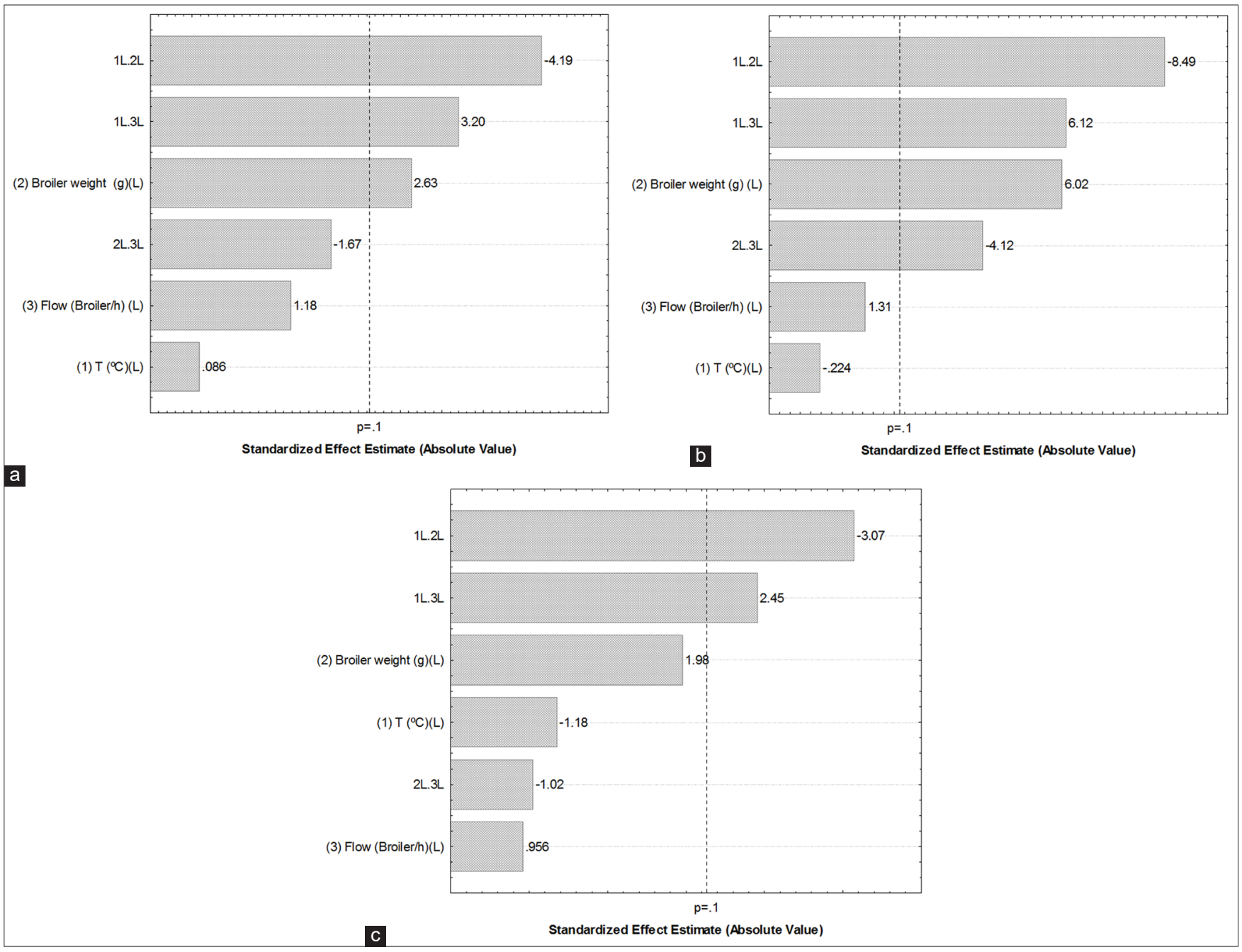

Fig 5. Pareto chart with the estimated effect (absolute value) for texture variables: gumminess (a), chewiness (b), and resilience (c) 
flow variables affect positively $(\mathrm{p}<0.10)$, however, the interaction between the broiler weight with flow and temperature affected negatively. Hardness and chewing being linked with the desirable chewing sensation of the meat portions (Sanchez Brambila et al., 2017). Although the hardness was not significantly affected, the treatments were sufficient to cause variations in the energy needed to chew, suggesting that the different parameters used in the scalding may influence the sensorial perceptions of the consumer in processed products.

The resilience (Fig. 5c) was affected negatively by the interaction between weight and temperature $(p<0.10)$, and positively by temperature and flow. The combination of variables, plus the comprehension strength were enough to affect the ability of the product to return to the state before suffering the deformation by compression.

Small changes in the parameters of gum, chewing and resilience may cause greater perceptions of cooked products, that is, the ability of the product to return to the state before suffer compression deformation, the desirable chewing sensation of meat portions.

Table 4 shows the results of the physical characteristics of broiler carcasses (absence of torn breast skin, epidermis, feather on wing and uropygium) in function of the independent variables. The temperature had a negative effect $(\mathrm{p}<0.05)$, where the high temperature resulted in an increase of torn breast skin (Fig. 6a). However, the processing line speed, weight and the interactions between the variables presented significant positive effect $(\mathrm{p}<0.05)$. With high processing line speed, the percentage of torn breast skin was low, considering that the processing line speed is related to the time that the carcasses remain in the scalding tank and defeathering. This result corroborates with Abraham et al. (2015) which emphasize that high exposure times and temperatures weakening the broiler skin, that can be a tear in the de-feathered stage.

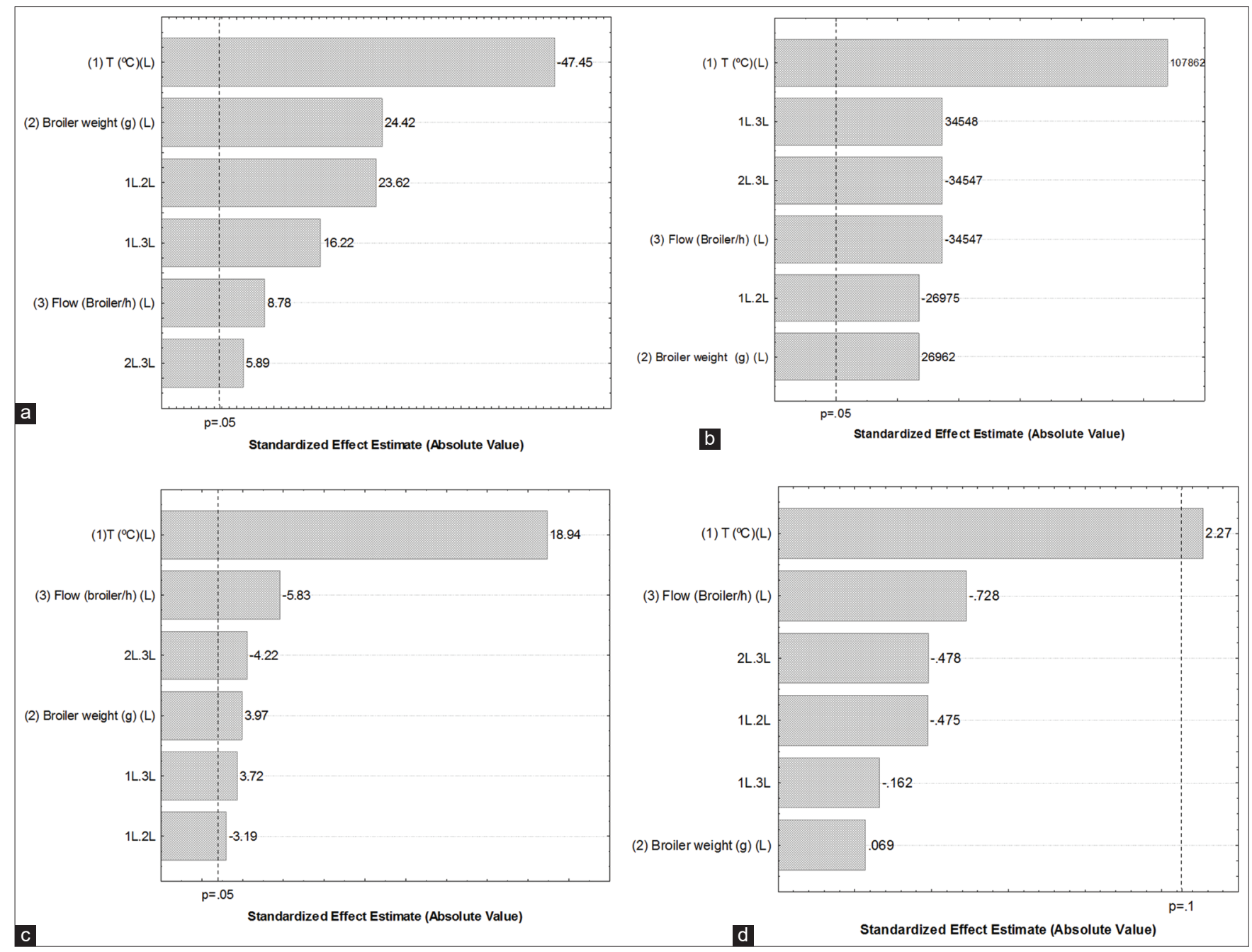

Fig 6. Pareto chart with the estimated effect (absolute value) for the percentage of absence of torn breast skin (a), absence of epidermis (b), absence of feather on wing (c), and absence of feather on uropygium (d) 
In relation to the absence of epidermis in the Pareto chart (Fig. 6b) it is verified that the temperature and broiler weigh

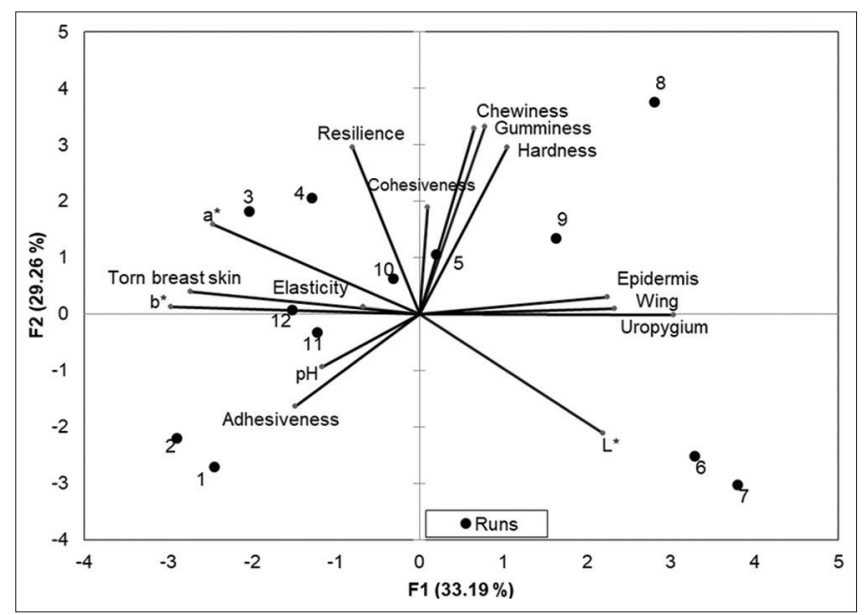

Fig 7. Principal Component Analysis (PCA) of the physical characteristics (color, $\mathrm{pH}$, and texture profile) of broiler carcasses variables had a significant positive effect $(\mathrm{p}<0.05)$, that is, low residual percentage of the epidermis in the carcasses in high levels. However, the broiler processing line speed had a significant negative effect $(p<0.05)$, that is, as the processing line speed increases. There is an increase in the residual of epidermis, because decreases the permanence time of the carcasses in the scalding tank, decreasing the time. Barbut (2015) affirm that larger broilers can make the de-feathering fingers act with greater intensity on the broiler skin and consequently there is a greater withdrawal of epidermis, once industries use machines with thousands of rubber fingers assembled in rotating drum. In addition, high temperatures tend to remove most or all outer layer of the epidermis, while low temperatures in the scalding may keep the epidermis intact.

The epidermis is the top layer of the skin and your removal is facilitate increasing the exposure time in the scalding tank. In Table 3 is not seen (Runs 1 to 4 ) the removal of

Table 2: Matrix of the experimental design $2^{3}$ (real and coded values) and values of texture profile (hardness, adhesiveness, elasticity, cohesiveness, gumminess, chewiness, and resilience) in broiler carcasses

\begin{tabular}{|c|c|c|c|c|c|c|c|c|c|c|}
\hline \multirow[t]{2}{*}{ Runs } & \multicolumn{3}{|c|}{ Independents variables } & \multicolumn{7}{|c|}{ Response } \\
\hline & $X_{1}$ & $X_{2}$ & $\mathrm{X}_{3}$ & Hardness & Adhesiveness & Elasticity & Cohesiveness & Gumminess & Chewiness & Resilience \\
\hline 1 & $-1(52)$ & $-1(2.6-2.8)$ & $-1(4000)$ & 4.491 & -122 & 0.90 & 0.70 & 3.110 & 2.914 & 0.48 \\
\hline 2 & $-1(52)$ & $+1(3.4-3.6)$ & $-1(4000)$ & 4.310 & -91.78 & 0.95 & 0.70 & 3.044 & 2.876 & 0.48 \\
\hline 3 & $-1(52)$ & $-1(2.6-2.8)$ & $+1(9000)$ & 5.298 & -99.29 & 0.96 & 0.71 & 3.821 & 3.729 & 0.52 \\
\hline 4 & $-1(52)$ & $+1(3.4-3.6)$ & $+1(9000)$ & 5.171 & -74.76 & 1.03 & 0.72 & 3.736 & 3.372 & 0.53 \\
\hline 5 & $+1(62)$ & $+1(3.4-3.6)$ & $+1(9000)$ & 5.101 & -116.40 & 0.94 & 0.71 & 3.689 & 3.471 & 0.51 \\
\hline 6 & $+1(62)$ & $-1(2.6-2.8)$ & $+1(9000)$ & 4.732 & -119.46 & 0.98 & 0.69 & 3.278 & 3.194 & 0.47 \\
\hline 7 & $+1(62)$ & $-1(2.6-2.8)$ & $-1(4000)$ & 4.654 & -121.67 & 0.95 & 0.69 & 3.241 & 3.073 & 0.48 \\
\hline 8 & +1 (62) & $+1(3.4-3.6)$ & $-1(4000)$ & 5.705 & -145.14 & 0.95 & 0.73 & 4.194 & 3.964 & 0.53 \\
\hline 9 & $0(57)$ & $0(3.0-3.2)$ & $0(6500)$ & 5.519 & -147.69 & 0.93 & 0.68 & 3.082 & 3.549 & 0.49 \\
\hline 10 & $0(57)$ & $0(3.0-3.2)$ & $0(6500)$ & 5.027 & -107.62 & 0.95 & 0.71 & 3.596 & 3.404 & 0.50 \\
\hline 11 & $0(57)$ & $0(3.0-3.2)$ & $0(6500)$ & 4.377 & -98.66 & 0.97 & 0.70 & 3.104 & 2.991 & 0.51 \\
\hline 12 & $0(57)$ & $0(3.0-3.2)$ & $0(6500)$ & 4.516 & -82.15 & 1.03 & 0.73 & 3.331 & 3.426 & 0.52 \\
\hline
\end{tabular}

$\mathrm{X}_{1}=$ Temperature ${ }^{\circ} \mathrm{C}, \mathrm{X}_{2}=$ Broiler weight $(\mathrm{kg}), \mathrm{X}_{3}=$ Processing line speed (broiler/h), Independent variables electric shock $(60 \mathrm{~V}$ and $850 \mathrm{~Hz})$, bleed time $(3 \mathrm{~min})$, volume in the scalding tank $(9000 \mathrm{~L})$, water temperature in the de-feather $\left(50 \pm 5^{\circ} \mathrm{C}\right)$ and bubbling in the scalding tanks $(11.7 \mathrm{kPa})$ and 31 broilers by run

Table 3: Matrix of the experimental design $2^{3}$ (real and coded values) and values of visual aspect of broiler carcasses with absence of torn breast skin, epidermis, feather on wing and uropygium

\begin{tabular}{|c|c|c|c|c|c|c|c|}
\hline \multirow[t]{2}{*}{ Runs } & \multicolumn{3}{|c|}{ Independent variables* } & \multicolumn{4}{|c|}{ Response (\%) } \\
\hline & $X_{1}$ & $X_{2}$ & $X_{3}$ & $\begin{array}{c}\text { Torn } \\
\text { breast skin } \\
\end{array}$ & $\begin{array}{l}\text { Absence of } \\
\text { epidermis }\end{array}$ & $\begin{array}{c}\text { Absence of feather } \\
\text { on wing }\end{array}$ & $\begin{array}{c}\text { Absence of feather } \\
\text { on uropygium }\end{array}$ \\
\hline 1 & $-1(52)$ & $-1(2.6-2.8)$ & $-1(4000)$ & 100 & 0 & 0 & 0 \\
\hline 2 & $-1(52)$ & $+1(3.4-3.6)$ & $-1(4000)$ & 97.30 & 0 & 0 & 0 \\
\hline 3 & $-1(52)$ & $-1(2.6-2.8)$ & $+1(9000)$ & 100 & 0 & 0 & 0 \\
\hline 4 & $-1(52)$ & $+1(3.4-3.6)$ & $+1(9000)$ & 97.30 & 0 & 0 & 0 \\
\hline 5 & $+1(62)$ & $+1(3.4-3.6)$ & $+1(9000)$ & 100 & 100 & 94.05 & 55.68 \\
\hline 6 & $+1(62)$ & $-1(2.6-2.8)$ & $+1(9000)$ & 35.14 & 100 & 98.38 & 100 \\
\hline 7 & $+1(62)$ & $-1(2.6-2.8)$ & $-1(4000)$ & 0.00 & 100 & 100 & 100 \\
\hline 8 & $+1(62)$ & $+1(3.4-3.6)$ & $-1(4000)$ & 5.41 & 100 & 85.95 & 82.70 \\
\hline 9 & $0(57)$ & $0(3.0-3.2)$ & $0(6500)$ & 100 & 100 & 90.81 & 100 \\
\hline 10 & $0(57)$ & $0(3.0-3.2)$ & $0(6500)$ & 97.30 & 100 & 86.49 & 74.59 \\
\hline 11 & $0(57)$ & $0(3.0-3.2)$ & $0(6500)$ & 100 & 100 & 84.86 & 74.10 \\
\hline 12 & $0(57)$ & $0(3.0-3.2)$ & $0(6500)$ & 100 & 100 & 97 & 74.21 \\
\hline
\end{tabular}

${ }^{*} \mathrm{X} 1=$ Temperature ${ }^{\circ} \mathrm{C}, \mathrm{X} 2=$ Broiler weight $(\mathrm{kg}), \mathrm{X} 3=$ Processing line speed (broiler/h), Independent variables electric shock $(60 \mathrm{~V}$ and $850 \mathrm{~Hz})$, bleed time $(3 \mathrm{~min})$, volume in the scalding tank $(9000 \mathrm{~L})$, water temperature in the de-feather $\left(50 \pm 5^{\circ} \mathrm{C}\right)$ and bubbling in the scalding tanks $(11.7 \mathrm{kPa})$ and 31 broilers by run 
the epidermal layer using $52^{\circ} \mathrm{C}$. Thus, this temperature is inefficient for the epidermis removal, which would cause high economic losses to the industry which need to discard carcasses with epidermis, they are not in agreement with the sanitary point of view (MAPA 1998). In this sense, it is necessary use temperatures close to $57^{\circ} \mathrm{C}$ for the epidermis removal, since the runs showed epidermal layer removal in $100 \%$ of the carcasses.

The estimated effects for the absence of feather on the wing are presented in Fig. 6c. The interaction temperature and broiler weight variables presented negative effect $(p<0.05)$, and the temperature and flow presented positive effect. The increase in these parameters resulted in low residual feathers on the wings. However, the broiler processing line speed presented a significant negative effect $(p<0.05)$, with low processing line speed decrease the residual percentage of feathers in the wing. The feathers detachment and consequent removal is facilitated by the use of high water temperature, which stimulates a skin porosity (loosening feathers from their follicles). Also, in the de-feathering stage, it is very important to adjust the machine according to the broiler size, regulating the rubber fingers pressure, and considered the weight, wherein larger broilers a more intense action of the de-feathering finger can occur on the carcasses (Barbut 2015).

In relation to the effect of the broiler processing line speed variable, again, it is observed that increasing the processing line speed decreasing the length time in the scalding tank and in the de-feathering, thus reducing the efficiency of the feathering, which consequently increases the residual of feathers on the wings.

Fig. 6d shows the estimated effects for the absence of feather on uropygium, where only the temperature presented a significant positive effect $(\mathrm{p}<0.10)$. In a similar way of the feather on skin, the high temperature resulted in low feather on uropygium. The high temperature causes an increase in pore sizes, with the humidification in the scaling tank increases the feathers density and the friction area facilitating the de-feathering.

Analyzing the feather residuals results on the wings and uropygium, it is verified that some runs, using the same parameters, have a greater removal in the wing (up to $76 \%$ ) compared to the uropygium. This may be due to the back region be difficult the feather fingers to access this area (Barbut 2015).

Table 4 and Fig. 7 present Pearson's correlation and principal component analysis (PCA) of the physical characteristics, color, $\mathrm{pH}$ and texture profile of broiler

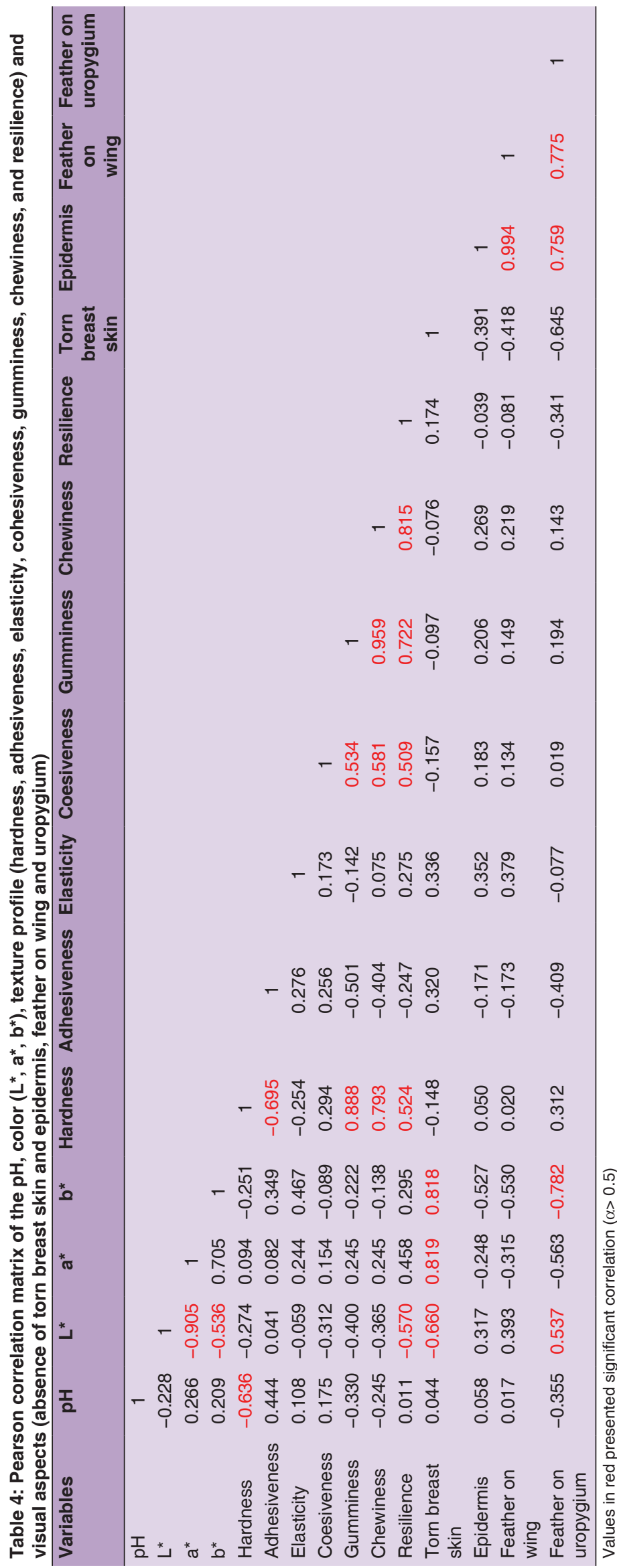

Emir. J. Food Agric • Vol 31 • Issue $11 \bullet 2019$ 
carcasses, respectively. Fig. 7 shows the PCA, where the variables (physical characteristics, color, $\mathrm{pH}$, and texture profile) are represented as vectors. The longer vector represent the better explanation of the variability among the variables. The first (CP1) and second (CP2) dimensions explained $62.45 \%$ of the total variance, with the main component 1 (CP1) accounting for $33.19 \%$, while the main component 2 (CP2) accounted for $29.26 \%$. It is observed that the values obtained by Pearson's correlation (Table 4) confirm a relation between the parameters observed in the PCA (Fig. 7), and where the hardness presents a positive correlation with gumminess, chewing and resilience $(0.888$, 0.793 , and 0.524 , respectively). However, the hardness presented a negative correlation $(-0.695)$ in relation to the adhesiveness.

The color $\mathrm{L} *$ (Table 4) presented a negative correlation in relation to $\mathrm{a}^{*}$ and $\mathrm{b}^{*}$ of -0.905 and -0.536 , respectively. The Runs next to the variables show a separation of the variables, demonstrating a differentiation between the samples with different treatments, where the Runs 6 and 7 showed more luminosity and the 3 and 4 more red color. This demonstrates that increasing the brightness in the middle breast decreases the intensities of red and yellow colors. In addition, a strong correlation between the absence of torn breast skin with the absence of feathers on wings and uropygium is observed, where the Run 9 was near to this variables.

\section{CONCLUSIONS}

Under industrial conditions it is suggested the use of scaling temperatures close to $57^{\circ} \mathrm{C}$, broiler weight of 3.0 to $3.2 \mathrm{~kg}$ and broiler processing line speed of 6500 broiler/h, to increase the efficiency of epidermis removal and absence of feathers on wings and uropygium. In addition, to maintain the quality of the middle chicken breast in relation to color $\left(\mathrm{L}^{*}, \mathrm{a}^{*}, \mathrm{~b}^{*}\right)$, texture profile (hardness, adhesiveness, elasticity, cohesiveness, gumminess, chewiness, and resilience) and $\mathrm{pH}$.

\section{CONFLICT OF INTEREST}

The authors declare no conflict of interest, financial or otherwise.

\section{ACKNOWLEDGEMENT}

This study was financed in part by the National Council for Scientific and Technological Development - Brazil (CNPq), Coordination for the Improvement of Higher Education Personnel - Brazil (CAPES) - Finance Code 001 and Research Support Foundation of the State of Rio Grande of Sul - Brazil (FAPERGS).

\section{Author's contributions}

Edson Anghinoni; Daniele Hamann study design of the experiments in industrial scale, Rogerio Luis Cansian, Alexander Junges, Eunice Valduga supervision of study, made the statistical analysis, and wrote the article. Clarice Steffens contributed to writing of discussions.

\section{REFERENCES}

Abraham, J. P., B. Plourde, L. Vallez, J. Stark and K. R. Diller. 2015. Estimating the time and temperature relationship for causation of deep-partial thickness skin burns. Burns. 41(8): 1741-1747.

Ali, S., W. Zhang, N. Rajput, M. A. Khan, C. B. Li and G. H. Zhou. 2015. Effect of multiple freeze thaw cycles on the quality of chicken breast meat. Food Chem. 173: 808-814.

AOAC. 2005. Official Methods of Analysis. Association of Official Analytical Chemists, Maryland, US.

Barbut, S. 2015. The Science of Poultry and Meat Processing. Poultry Meat Process Quality. University of Guelph, Ontario, Canada.

Bowker, B. C. and H. Zhuang. 2013. Relationship between Muscle exudate protein composition and broiler breast meat quality. Poult. Sci. 92(5): 1385-1392.

Bowker, B. C., H. Zhuang and R. J. Buhr. 2014. Impact of carcass scalding and chilling on muscle proteins and meat quality of broiler breast fillets. LWT Food Sci. Technol. 59(1): 156-162.

Buhr, R. J., J. M. Walker, D. V. Bourassa, A. B. Caudill, B. H. Kiepper and $\mathrm{H}$. Zhuang. 2014. Impact of broiler processing scalding and chilling profiles on carcass and breast meat yield. Poult. Sci. 93(6): 1534-1541.

Chatterjee, D., H. Zhuang, B. C. Bowker, A. M. Rincon and G. Sanchez-Brambila. 2016. Instrumental texture characteristics of broiler pectoralis major with the wooden breast condition. Poult. Sci. 95(10): 2449-2454.

Droval, A. A., V. T. Benassi, A. Rossa, S. H. Prudencio, F. G. Paião and M. Shimokomaki. 2012. Consumer attitudes and preferences regarding pale, soft, and exudative broiler breast meat. J. Appl. Poult. Res. 21(3): 502-507.

FAO. 2018. Meat Market Review. Food and Agriculture Organization, United States.

Husak, R. L., J. G. Sebranek and K. Bregendahl. 2008. A survey of commercially available broilers marketed as organic, free range, and conventional broilers for cooked meat yields, meat composition, and relative value. Poult. Sci. 87(11): 2367-2376.

Jeong, J. Y., K. K. Janardhanan, A. M. Booren, D. M. Karcher and I. Kang. 2011. Moisture content, processing yield, and surface color of broiler carcasses chilled by water, air, or evaporative air. Poult. Sci. 90(3): 687-693.

King, N. J. and R. Whyte. 2006. Does it look cooked? A review of factors that influence cooked meat color. J. Food Sci. 71(4): 31-40.

King, T., M. Cole, J. M. Farber, G. Eisenbrand, D. Zabaras, E. M. Fox and J. P. Hill. 2017. Food safety for food security: Relationship between global megatrends and developments in food safety. Trends Food Sci. Technol. 68: 160-175.

Lorenzetti, E., B. M. S. Puton, I. A. Fernandes, N. V. Prado, R. Frigotto, S. S. Roman, A. Junges, C. Steffens, J. Zeni, J. Steffens, G. T. Backes, R. L. Cansian and E. Valduga. 2018. Water absorption and dripping of chicken breast and carcasses during pre-cooling in an industrial system. Poult. Sci. 97(12): 4462-4469.

Lorenzetti, E., J. Soares, H. Treichel, R. L. Cansian, C. Steffens 
and E. Valduga. 2015. Brine absorption in seasoned chicken pieces. J. Consum. Prot. Food Saf. 10: 331-340.

MAPA. 1998. Portaria No 210, de 10 de Novembro de 1998. Publicado No Diário Oficial Da União, Seção 1. Ministério da Agricultura e Pecuária, Brazil, p. 226.

Mc Carthy, U., I. Uysal, R. Badia-Melis, S. Mercier, C. O'Donnell and A. Ktenioudaki. 2018. Global food security issues, challenges and technological solutions. Trends Food Sci. Technol. 77: 11-20.

Qiao, M., D. L. Fletcher, D. P. Smith and J. K. Northcutt. 2001. The effect of broiler breast meat color on $\mathrm{PH}$, moisture, water-holding capacity, and emulsification capacity. Poult. Sci. 80(5): 676-680.

Sanchez, B., G. D. Chatterjee, B. Bowker and H. Zhuang. 2017. Descriptive texture analyses of cooked patties made of chicken breast with the woody breast condition. Poult. Sci. 96(9): 3489-3494.

Santos, H. C., A. Brandelli and M. A. Z. Ayub. 2004. Influence of post-mortem aging in tenderness of chicken breast fillets. Ciência Rural. 34: 905-910. Available from: http:// www.scielo.br/scielo.php?script=sci_arttext\&pid=S010384782004000300038\&nrm=iso.

Soglia, F., S. Mudalal, E. Babini, M. Di Nunzio, M. Mazzoni, F. Sirri, C. Cavani and M. Petracci. 2016. Histology, composition, and quality traits of chicken pectoralis major muscle affected by wooden breast abnormality. Poult. Sci. 95(3): 651-659.

Zhuang, H., B. C. Bowker, R. J. Buhr, D. V. Bourassa and B. H. Kiepper. 2013. Effects of broiler carcass scalding and chilling methods on quality of early-deboned breast fillets. Poult. Sci. 92(5): 1393-1399. 